\title{
AVALIAÇÃO DO HIPOCLORITO DE SÓDIO E DA CLOREXIDINA NA DESINFECÇÃO DE CONES DE GUTA-PERCHA
}

\section{EVALUATION OF SODIUM HYPOCHLORITE AND CHLORHEXIDINE IN DISINFECTION GUTTA-PERCHA CONES}

\author{
Cynthia Cristina Gomes* \\ Izabel Coelho Gomes Camões* \\ Lílian Ferreira Freitas"* \\ Shirley de Souza Pinto**** \\ Sônia Magalhães Saraiva"**** \\ Solange Sambati ${ }^{\ldots+\cdots * *}$
}

\begin{abstract}
RESUMO
Introdução: O objetivo deste trabalho é avaliar a eficácia, em dois períodos de tempo, do hipoclorito de sódio e da clorexidina na desinfecção de cones de guta-percha. Métodos: Foram utilizados 50 cones de gutapercha previamente contaminados com cepas de bactérias do gênero Enterococcus faecalis (ATCC 29212), em culturas puras. Para o processo de descontaminação, os cones foram divididos em quatro grupos, contendo 10 amostras cada: G1- hipoclorito de sódio ( $\mathrm{NaOCl}$ ) a 5,25\% por 30 segundos; $\mathrm{G} 2$ - $\mathrm{NaOCl}$ a 5,25\% por 1 minuto; G3 - clorexidina a 4\% por 30 segundos; G4 - clorexidina a 4\% por 1 minuto. Após esse período, os cones foram introduzidos individualmente em tubos de ensaio contendo caldo de $\mathrm{BHI}$, mantidos em estufa bacteriológica a $37^{\circ} \mathrm{C}$ por 72 horas, quando foi avaliada a presença de contaminação através da turvação do meio. Para o grupo-controle positivo, empregaram-se 2 cones, que foram contaminados e colocados em tubos de ensaio e, para o controle negativo, 8 cones foram apenas descontaminados, sendo colocados 2 cones em cada uma das soluções desinfetantes, por 30 segundos e por 1 minuto. Resultados: Verificou-se a ausência de crescimento bacteriano nos grupos 1, 2, 3 e 4, em todos os períodos experimentais. No controle positivo, houve $100 \%$ de contaminação e, no controle negativo, ausência de crescimento bacteriano. Conclusão: As soluções de $\mathrm{NaOCl}$ a $5,25 \%$ e de clorexidina a $4 \%$, por períodos de tempo de 30 segundos e de 1 minuto, possuem efetividade antimicrobiana contra o Enterococcus faecalis, podendo ser utilizadas na desinfecção de cones de guta-percha nos tempos testados.
\end{abstract}

DESCRITORES: Compostos químicos • Guta-percha • Desinfecção.

\section{ABSTRACT}

Introduction: The aim of this study is to evaluate the efficacy, in two period of time, of sodium hypochlorite and chlorhexidine in disinfection gutta-percha cones. Methods: 50 gutta-percha cones were used, previously contaminated with bacteria of the genus Enterococcus faecalis (ATCC 29212), in pure cultures. For the decontamination process, the cones were divided into four groups, containing 10 samples each: G1- sodium hypochlorite 5,25\% for 30 seconds; G2 - sodium hypochlorite 5,25\% for 1 minute; G3 - chlorhexidine $4 \%$ for 30 seconds; G4 - chlorhexidine 4\% for 1 minute. After this period, all cones were immersed individually in test tubes containing Brain Heart Infusion, maintained in bacteriological incubator at $37^{\circ} \mathrm{C}$ for 72 hours, when was evaluated the presence of contamination through the turbidity of $\mathrm{BHI}$ solution. For the positive control groups, were used 2 gutta-percha cones that were contaminated and placed directly in test tubes and for the negative control group 8 cones were just decontaminated, being placed 2 cones in each disinfectant solution, for 30 seconds and for 1 minute. Results: There was the absence of bacterial growth in groups 1, 2, 3 and 4, in all experimental periods. In the positive control group were verified $100 \%$ of contamination and in the negative control tubes wasn't verified the presence of bacterial growth. Conclusion: The solutions of 5,25\% sodium hypochlorite and $4 \%$ chlorhexidine for 30 seconds and 1 minute have antimicrobial effectiveness against Enterococcus faecalis, which can be used in the disinfection of gutta-percha cones in the time tested.

DESCRIPTORS: Chemical compounds • Gutta-percha • Disinfection.

* Doutora em Endodontia pela Universidade do Estado do Rio de Janeiro - UERJ. Prof. da Disciplina de Endodontia da Universidade Federal Fluminense (UFF). Pólo Universitário Nova Friburgo, Rio de Janeiro, Brasil. e-mail:cigomez@terra.com.br

** Doutora em Odontologia pela Universidade Federal do Rio de Janeiro - UFRJ. Prof. da Disciplina de Endodontia do Departamento de Odontoclínica da Universidade Federal Fluminense -UFF. Niterói, Rio de Janeiro, Brasil. e-mail: icamões@netbotanic.com.br

*** Doutoranda em Endodontia pela Universidade do Estado do Rio de Janeiro - UERJ. Prof. da Disciplina de Endodontia do Departamento de Odontoclínica da Universidade Federal Fluminense - UFF. Niterói, Rio de Janeiro, Brasil. e-mail: lilianffreitas@uol.com.br

**** Doutoranda em Endodontia pela Universidade do Estado do Rio de Janeiro -UERJ. Prof. da Disciplina de Endodontia do Departamento de Odontoclínica da Universidade Federal Fluminense - UFF. Niterói, Rio de Janeiro, Brasil. e-mail: shirleysp_uff@yahoo.com.br

***** Especialista em Endodontia pela Universidade Federal Fluminense - UFF. e-mail: soniasaraiva_@ hotmail.com

****** Mestranda em Odontologia pela Universidade Federal Fluminense - UFF. e-mail: sosambatti@ hotmail.com 


\section{N T RO DUÇÃ O}

Para se obter sucesso na terapia endodôntica, deve-se realizar adequadamente todas as fases do tratamento, desde o acesso à câmara pulpar até a obturação do canal radicular, passando pela instrumentação com a limpeza e modelagem dos sistemas de canais radiculares, priorizando sempre a manutenção da cadeia asséptica em todas as etapas, a fim de reduzir o maior número possível de microrganismos do sistema de canais radiculares, aumentando-se as taxas de êxito do tratamento endodôntico. (Gahyva e Siqueira ${ }^{1}, 2001$ ).

O primeiro estudo microbiológico em endodontia data de 1894, quando Miller², após a análise de material coletado do interior de canais radiculares, fez a correlação entre bactérias e patologias pulpares e periapicais.

Através do estudo clássico da literatura endodôntica, Kakehashi et al. ${ }^{3}$, em 1965, confirmaram a importância das bactérias no desenvolvimento das doenças pulpares e perirradiculares, expondo a polpa dental de ratos convencionais e "germ-free" à cavidade oral, observando a formação de necrose pulpar e lesão perirradicular somente em ratos convencionais.

A redução ou eliminação dos microrganismos do sistema de canais radiculares e a prevenção da reinfecção dos canais obturados são alguns dos objetivos principais do tratamento endodôntico, sendo para isso fundamental o controle da infecção durante os procedimento operatórios (Machtou $\left.{ }^{4}, 1980\right)$.

De acordo com Leonardo et al. ${ }^{5}$ (1997), microrganismos não devem ser transportados, por instrumentos ou materiais endodônticos contaminados, para o interior do canal radicular, pois estes são responsáveis pela etiologia e persistência de patologias de origem endodôntica. Então, durante a fase da obturação, cujo objetivo é o preenchimento hermético e tridimensinal do sistema de canais radiculares, deve-se utilizar materiais descontaminados. A guta-percha, associada a cimentos endodônticos, é o material obturador mais usado mundialmente, por serem biocompatíveis, não interferindo no processo de reparação com os tecidos vivos e, por estarem em contato direto com os tecidos periapicais durante a obturação dos canais radiculares, faz-se necessário estudar meios viáveis de torná-los livres de microrganismos. Por esse motivo, alguns profissionais, desinfetam os cones com o intuito de não quebrar a cadeia de assepsia, que constitui um fator essencial para o sucesso do tratamento endodôntico. (Siqueira Jr et al. $\left.{ }^{6}, 1998\right)$.

A desinfecção dos cones de guta-percha é realizada, preferencialmente, por agentes químicos usados também na sanificação do conduto radicular (Estrela et al. $\left.{ }^{7}, 2002\right)$.

Walker e Love ${ }^{8}$ (1936) indicaram a utilização do hipoclorito de sódio a 5\% para o preparo de canais radiculares de dentes com polpas necrosadas, uma vez que auxilia na descontaminação dos instrumentos, manipulação dos canais radiculares e proteção do paciente e do operador, pois apresenta excelente atividade antibacteriana, relacionada com a formação de compostos contendo cloro ativo (como o ácido hipocloroso e o íon hipoclorito). $\mathrm{O}$ $\mathrm{NaOCl}$, em diferentes concentrações, tornou-se a solução auxiliar da instrumentação mais utilizada na terapia endodôntica (Hauman e Love ${ }^{9}, 2003$; Lopes e Siquei$\left.\mathrm{ra}^{10}, 2004\right)$

Porém, outra substância química que tem sido amplamente utilizada na Endodontia é a clorexidina, que começou a ser empregada para irrigação de canais radiculares em 1964, sendo atualmente categorizada terapeuticamente com ação antimicrobiana de atuação prolongada (substantividade) especialmente contra o Enterococcus faecalis e Cândida albicans, antisséptica tópica e desinfetante, usada com mais frequência na forma de sal solúvel em água, o digluconato de clorexidina, que apresenta maior estabilidade (Leonardo et al. ${ }^{11}, 1999$; Zamany et al. ${ }^{12}$, 2003; Basrani et al. ${ }^{13}$, 2002)

Pelo fato do cone de guta-percha ter alta porcentagem de óxido de zinco em sua composição e essa substância apresentar características antimicrobianas, alguns autores como Morais e Olmedo ${ }^{14}$ (1971) julgaram desnecessária a desinfecção prévia desse material.
GOMES CC, CAMÕES ICG, FREITAS LF, PINTO SS,

SARAIVA SM, SAMBATI $S$.

AVALIAÇÃo DO HIPOCLORITO DE SÓDIO E DA CLOREXIDINA NA DESINFECÇÃO DE CONES DE GUTAPERCHA
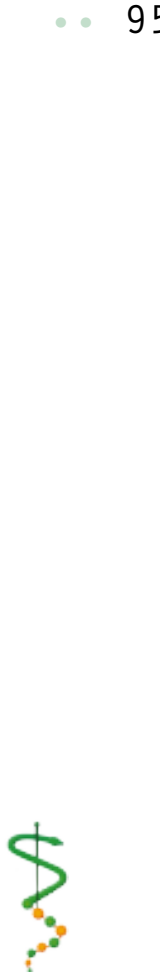

REVISTA DE ODONTOLOGIA DA UN I VERS I DADE Cidade de São PAULO

$2010 ; 22(2): 94-$ 103, MAI - AGO 
GOMES CC,

CAMÕES ICG,

FREITAS LF,

PINTO SS,

SARAIVA SM,

SAMBATI $S$.

AVALIAÇÃO DO

HIPOCLORITO

DE SÓDIO E DA

CLOREXIDINA NA

DES INFECÇÃO DE

CONES DE GUTA-

PERCHA

96

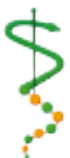

REVISTA DE

ODONTOLOGIA DA:

UNIVERSIDADE:

CIDADE DE SÃO

PAULO

$2010 ; 22(2): 94-$

103, MAI-AGO
Cardoso et $\mathrm{al}^{15}$. (2000) compararam a eficácia de sete agentes químicos, usados na prática odontológica, na descontaminação rápida de 32 cones de guta-percha aderidos com Staphylococcus aureus, Enterococcus faecalis, Escherichia coli ou esporos de Bacillus subtilis. Os cones foram tratados por 1, 5, 10 e 15 minutos com glutaraldeído a $2 \%$, hipoclorito de sódio a $1 \%$, álcool etílico a $70 \%$, álcool iodado a $0,3 \%$ e $1 \%$, clorexidina a $2 \%$, água oxigenada a $6 \%$ e polivinilpirrolidona-iodo a $10 \%$. Os produtos foram bactericidas após 1 a 5 minutos e esporicidas, com exceção do álcool e do álcool iodado, após 1 a 15 minutos de exposição. Os resultados sugeriram que a clorexidina, o hipoclorito, a polivinilpirrolidona-iodo, a água oxigenada e o glutaraldeído foram os produtos mais eficazes na descontaminação dos cones de guta-percha.

Gomes et al. ${ }^{16}$ (2001a) testaram a efetividade de cinco diferentes concentrações de hipoclorito de sódio $(0,5 \%, 1 \%$, $2,5 \%, 4 \%$ e 5,25\%) na descontaminação de cones de guta-percha artificialmente contaminados por diferentes tipos de microrganismos. Nenhum dos microrganismos cresceu a partir de 45 segundos de exposição ao $\mathrm{NaOCl}$ a 5,25\%. Os testes microbiológicos indicaram que o $\mathrm{NaOCl}$ é um método efetivo de descontaminação dos cones de guta-percha e o período de imersão necessário para atingir esse efeito é inversamente proporcional ao aumento da concentração.

Radcliffe et al. ${ }^{17}$ (2004) determinaram a resistência de microrganismos associados com infecções endodônticas refratárias, entre eles o E. faecalis, ao hipoclorito de sódio a $0,5,1,0,2,5$ e $5,25 \%$ por 0,10 , 20, 30, 60 e 120 segundos, sendo avaliado também nos intervalos de 1, 2, 5, 10 e 30 minutos. O número de Unidades Formadoras de Colônias (UFC) do E. faecalis foi reduzido a zero após 30 minutos com a concentração de $0,5 \%, 10$ minutos a 2,5\%, e 2 minutos a 5,25\%.

Fagundes et al. ${ }^{18}$ (2005) verificaram a eficiência de diferentes soluções na descontaminação de cones de guta-percha expostos ao Enterococcus faecalis. Utilizaram-se 80 cones, separados em 8 grupos (10 cones cada). Foram contaminados
70 cones com Enterococcus faecalis e depois os grupos sofreram descontaminação: - G1: álcool a 70\%, G2: álcool a 70\% + iodo a 1\%, G3: álcool a 70\% + clorexidina a 4\%, G5: $\mathrm{NaOCl}$ a 2,5\%, G6: $\mathrm{NaOCl}$ a 5,25\%, G7: solução salina, G8: não foi contaminado e não sofreu descontaminação (controle). Os cones foram mantidos nas soluções por 1 e 5 minutos. Observaram que no tempo de um minuto houve crescimento bacteriano nos grupos 1, 2, 5 e 7. Concluíram que a associação de álcool a $70 \%$ com clorexidina a $4 \%$ e $\mathrm{NaOCl}$ a 5,25\% não permitiu o desenvolvimento de Enterococcus faecalis, promovendo boa desinfecção dos cones de guta-percha num tempo adequado para a prática clínica.

Vários trabalhos avaliaram a eficácia e as alternativas de medicamentos para eliminar o biofilme do Enterococcus faecalis, devido ao fato dele estar associado com fracassos da terapia endodôntica e por ser um microrganismo encontrado em infecções endodônticas persistentes. A ação antibacteriana eficaz da clorexidina, em diferentes concentrações, contra o E. faecalis, foi demonstrada por diversos autores. Os resultados indicaram que essa solução pode ser empregada em casos refratários à terapia endodôntica convencional. A clorexidina apresentou boa eficácia contra E. faecalis, no entanto, essa eficácia é diretamente dependente da concentração (Lima et al. ${ }^{19}$, 2001; Basrani et al. ${ }^{13}, 2002$; Zamany et al. ${ }^{12}$, 2003).

Em recente estudo, Dametto et al. ${ }^{20}$ (2005) verificaram que não houve diferenças significantes em termos de redução de unidades formadoras de colônia de $E$. faecalis comparando-se clorexidina em gel a $2 \%$, clorexidina líquida a $2 \%$ e hipoclorito de sódio a $5,25 \%$.

Redmerski et al. ${ }^{21}$ (2007) estudaram o desempenho das soluções aquosa e detergente de digluconato de clorexidina a $2 \%$ na descontaminação de cones de guta-percha contaminados experimentalmente pelos seguintes microrganismos: Staphylococcus aureus, Enterococcus faecalis, Escherichia coli e Cândida albicans. Esporos de Bacillus subtilis foram também testados. Os cones contaminados foram tratados com as soluções de clorexidina 
por, respectivamente, 1, 5, 10 ou $15 \mathrm{~min}$. As soluções de clorexidina destruíram em 1 min as células de $S$. aureus, $E$. faecalis e de C. albicans. E. coli foi eliminada em 5 min com a solução detergente. Os esporos de Bacillus subtilis foram eliminados pelas soluções de clorexidina em $5 \mathrm{~min}$. Os resultados deste estudo demonstraram que as soluções de clorexidina a $2 \%$ foram efetivas na descontaminação dos cones de guta- percha em 5 minutos.

Apesar do registro na literatura de diversos métodos, incluindo o emprego de diferentes agentes químicos, não existe um consenso entre os especialistas sobre a técnica a ser usada para a desinfecção rápida de cones obturadores dos canais radiculares no consultório odontológico (Linke e Chohayeb ${ }^{22}, 1983$; Cardoso et al. ${ }^{15}$, 2000; Gomes et al. ${ }^{16}, 2001$ a, Gomes et al. ${ }^{23}, 2001 \mathrm{~b}$ ).

Realizar a desinfecção de cones de guta-percha utilizados na prática endodôntica vem a ser relevante para que a cadeia asséptica seja respeitada, uma vez que a utilização de um material contaminado no interior do canal radicular pode comprometer o sucesso da terapia endodôntica.

Entretanto, os cones de guta-percha, por não resistirem aos processos convencionais de esterilização, que utilizam calor úmido ou seco, que elevam a temperatura e causam a sua deformação, necessitam ser desinfetados por agentes químicos (Linke e Chohayeb ${ }^{22}$, 1983; Leonardo et al. ${ }^{5}, 1997$; Cardoso et al. ${ }^{15}$, 2000).

Considerando-se as soluções de hipoclorito de sódio e de clorexidina como

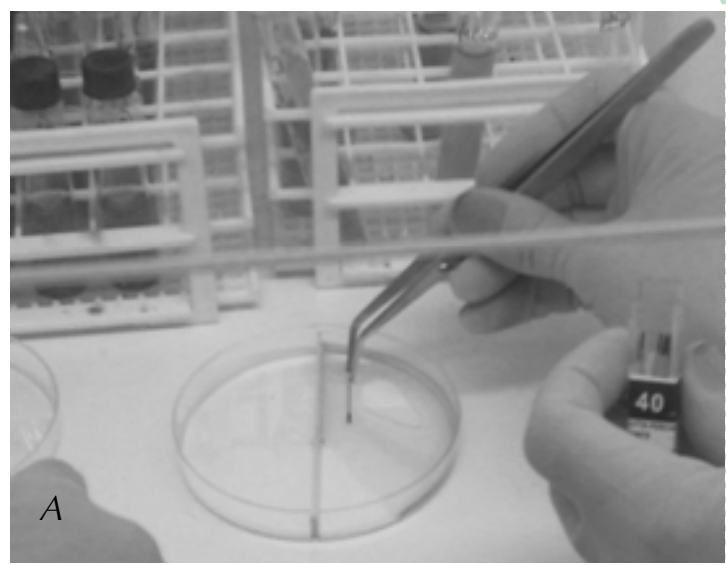

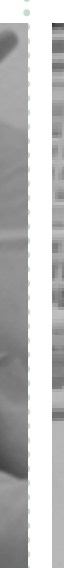

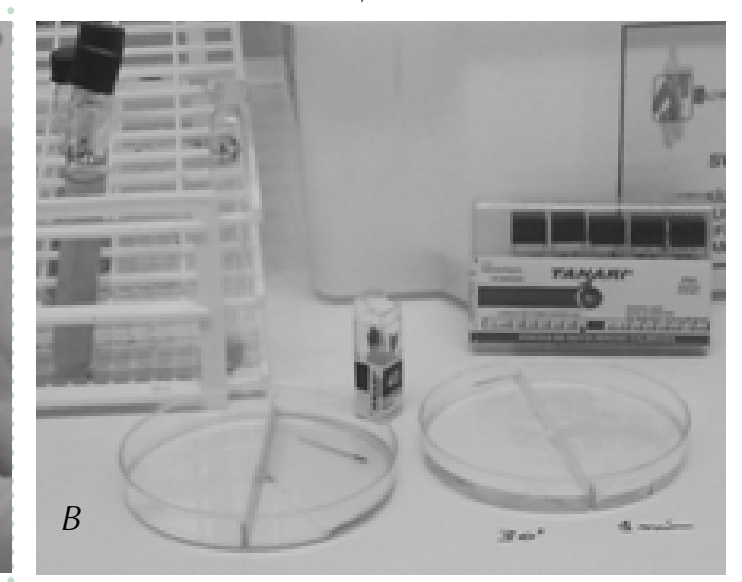

Figura 1 - (a) e (b) - Contaminação dos cones. Cada cone foi removido de embalagens lacra-
das com o auxílio de pinças esterilizadas e imersos em suspensão micro-

Figura 1 - (a) e (b) - Contaminação dos cones. Cada cone foi removido de embalagens lacra-
das com o auxílio de pinças esterilizadas e imersos em suspensão microbiana (placa de Petri) por 1 minuto.

potentes agentes antimicrobianos e tendose em vista a necessidade de se conseguir uma rápida descontaminação dos cones de guta-percha a fim de se manter a cadeia asséptica em todas as etapas do tratamento endodôntico, com isso aumentando-se o percentual de êxito das terapias, esta pesquisa tem como objetivo avaliar a eficácia do hipoclorito de sódio a 5,25\% e da clorexidina a $4 \%$ na desinfecção dos cones de guta-percha previamente contaminados com Enterococcus faecalis, que é muito encontrado em infecções endodônticas persistentes, nos períodos de tempo de 30 segundos e de 1 minuto.

\section{MATERIAL E MÉTODO}

Foram utilizados 50 (cinquenta) cones de guta-percha (Tanari $\AA$, Manacapuru, AM, Brasil) de calibre 40, de embalagens lacradas. Os cones sofreram uma contaminação prévia com cepas de bactérias do gênero Enterococcus faecalis proveniente da American Type Culture Collection (ATCC 29212 - 02/07/07- Manassas -USA), em culturas puras. O inócuo foi preparado através da semeadura em placas de Petri contendo Agar infusão de cérebro-coração (Brain Heart Infusion Agar, BHI), incubadas em estufa bacteriológica a $37^{\circ} \mathrm{C}$ por 24 horas. Após o crescimento bacteriano, foi realizada a suspensão em solução fisiológica estéril ( $\mathrm{NaCl}$ a $0,9 \%$ ), procedendo-se ao ajuste da cultura de acordo com a escala de McFarland.

Os cones foram retirados ao acaso, individualmente, de diversas embalagens comerciais lacradas, abertas com o uso de
GOMES CC, CAMÕES ICG. FREITAS LF, PINTO SS,

SARAIVA SM, SAMBATI $S$.

AVALIAÇÃO DO HIPOCLORITO

DE SÓDIO E DA CLOREXIDINA NA DESINFECÇÃO DE CONES DE GUTAPERCHA
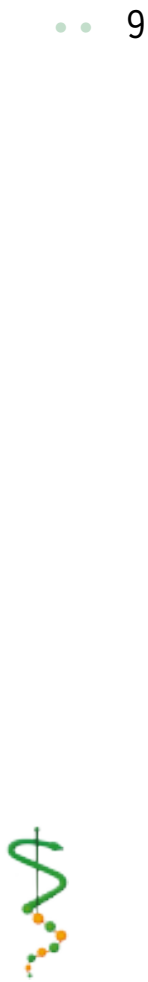

REVISTA DE ODONTOLOGIA DA UNI VERS I DADE Cidade de São PAULO

$2010 ; 22(2): 94-$ 103, MAI - AGO 
GOMES CC,

CAMÕES ICG,

FREITAS LF,

PINTO SS,

SARAIVA SM,

SAMBATI $S$.

AVALIAÇÃO DO

HIPOCLORITO

DE SÓDIO E DA

CLOREXIDINA NA

DESINFECÇÃO DE

CONES DE GUTA-

PERCHA lâminas de bisturi estéreis e com o auxílio de pinças esterilizadas e cada cone foi imerso em parte da suspensão microbiana contendo Enterococcus faecalis, em placas de Petri (lisas, estéreis e descartáveis de $90 \times 15 \mathrm{~mm})$, por 1 minuto, para que houvesse a contaminação (Figura 1, a e b).

A seguir, para o processo de desinfecção, os cones foram divididos, aleatoriamente, em quatro grupos, contendo 10 amostras cada, de acordo com a solução desinfetante e o tempo de exposição. Cada cone foi removido, com o auxílio de pinças esterilizadas, e transferido à placa estéril de Petri (uma para cada grupo), onde as soluções desinfetantes foram colocadas.

No Grupo 1 (G1), foi utilizado hipoclorito de sódio ( $\mathrm{NaOCl}$ - Egal Farmácia de Manipulação - RJ) a 5,25\% por 30 segundos; no G2 foi utilizado $\mathrm{NaOCl}$ a $5,25 \%$ por 1 minuto; no G3 foi utilizada a clorexidina a $4 \%$ (Egal Farmácia de Manipulação - RJ) por 30 segundos e no Grupo 4 (G4) a clorexidina a $4 \%$ por 1 minuto. A seguir, os cones foram secos em gaze estéril e introduzidos individualmente em tubos de ensaio rosqueáveis, contendo $5 \mathrm{ml}$ de caldo de cultura BHI, e identificados de acordo com os grupos (Figura 2, a e b).
Dois grupos-controles foram empregados, o grupo-controle positivo, contendo 2 cones de guta-percha que foram contaminados por 1 minuto com Enterococcus faecalis e imediatamente inseridos em tubos de ensaio contendo caldo $\mathrm{BHI}$, sem que antes fossem descontaminados pelas soluções desinfetantes e o grupo-controle negativo com 8 cones que não sofreram uma contaminação prévia e que foram descontaminados pela imersão de 2 cones em cada uma das soluções desinfetantes, sendo 2 cones imersos no $\mathrm{NaOCl}$ a $5,25 \%$ por 30 segundos, 2 cones imersos no $\mathrm{Na}$ $\mathrm{OCl}$ a $5,25 \%$ por 1 minuto, 2 na clorexidina a $4 \%$ por 30 segundos e 2 na clorexidina a $4 \%$ por 1 minuto. Logo após, foram colocados nos tubos de ensaio contendo caldo BHI (Figura 3).

Todos os tubos contendo caldo de $\mathrm{BHI}$ (Figura 4) foram levados à estufa bacterio-

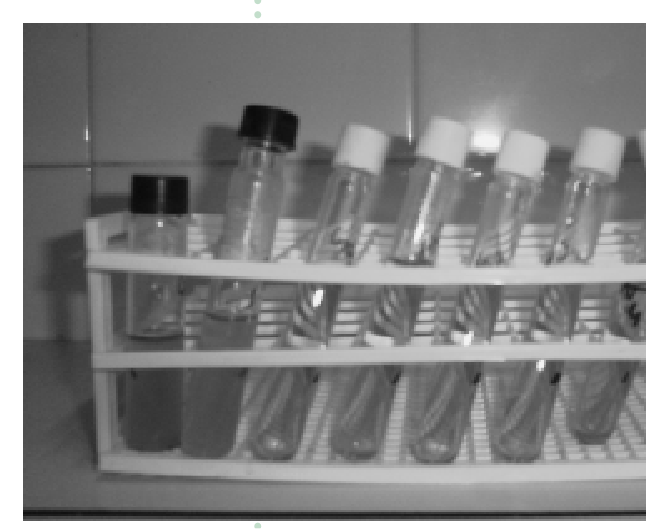

Figura 3 - Grupo-controle positivo, com 2 cones em tubos de ensaio de tampa rosqueável preta e o grupo-contole negativo com 8 cones em tubos de ensaio de tampa rosqueável branca.

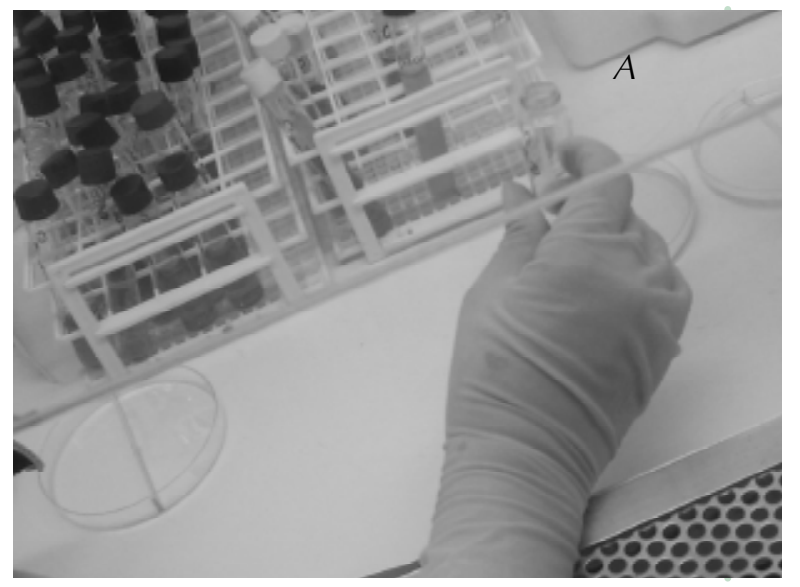

Figura 2 - (a) e (b) - Manipulação dos cones, sendo removidos das soluções desinfetantes

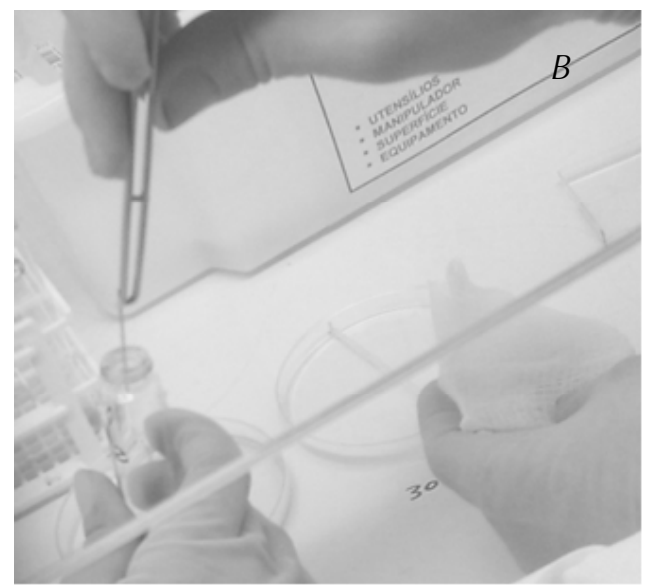

UNIVERSIDADE: PAULO
(placas de Petri), depois secos com gaze estéril e introduzidos em tubos de ensaio, em ambiente asséptico.




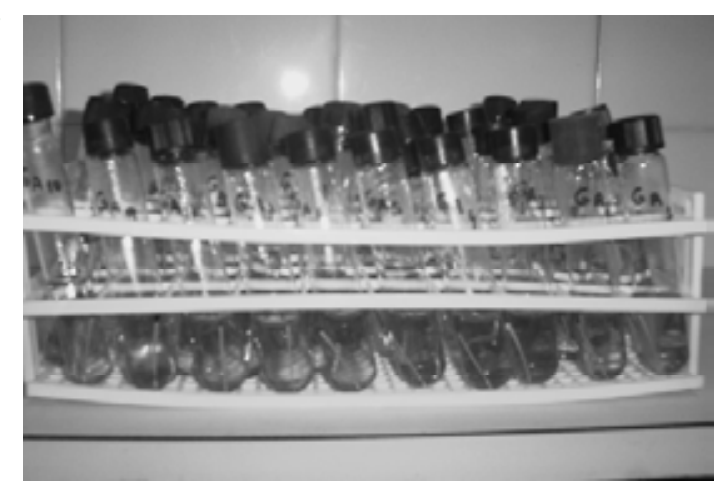

Figura 4 - Os 50 tubos de ensaio contendo 1 cone cada, imersos em caldo de BHI.

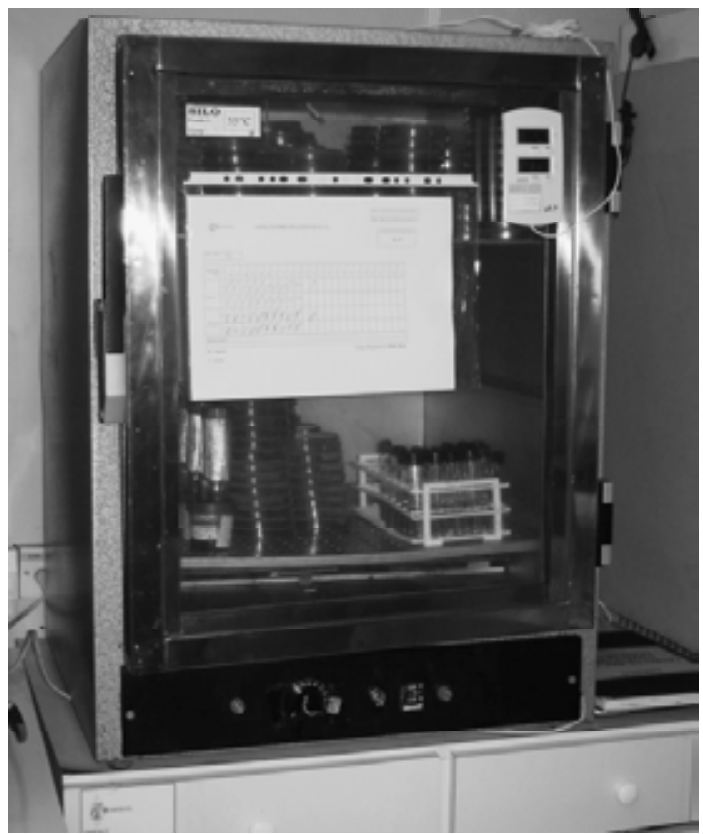

Figura 5 - Estufa bacteriológica com os tubos de ensaio, onde foram incubados a uma temperatura de $37^{\circ} \mathrm{C}$ por 72 horas.

lógica (Fanem-SP), onde permaneceram incubados a uma temperatura de $37^{\circ} \mathrm{C}$ por um período de 72 horas (Figura 5).

A avaliação da contaminação foi feita por análise visual através da turvação do meio de cultura. Os tubos de ensaio que apresentaram turbidez do caldo de $\mathrm{BHI}$ foram considerados positivos (houve crescimento bacteriano) e os tubos de ensaio que se apresentaram límpidos foram considerados negativos (sem crescimento bacteriano), como demonstrados na Figura 6.

O estudo foi executado em condições totalmente assépticas, dentro de uma capela de fluxo laminar (Veco Classe II B II - SP), previamente preparada conforme as normas microbiológicas de assepsia,

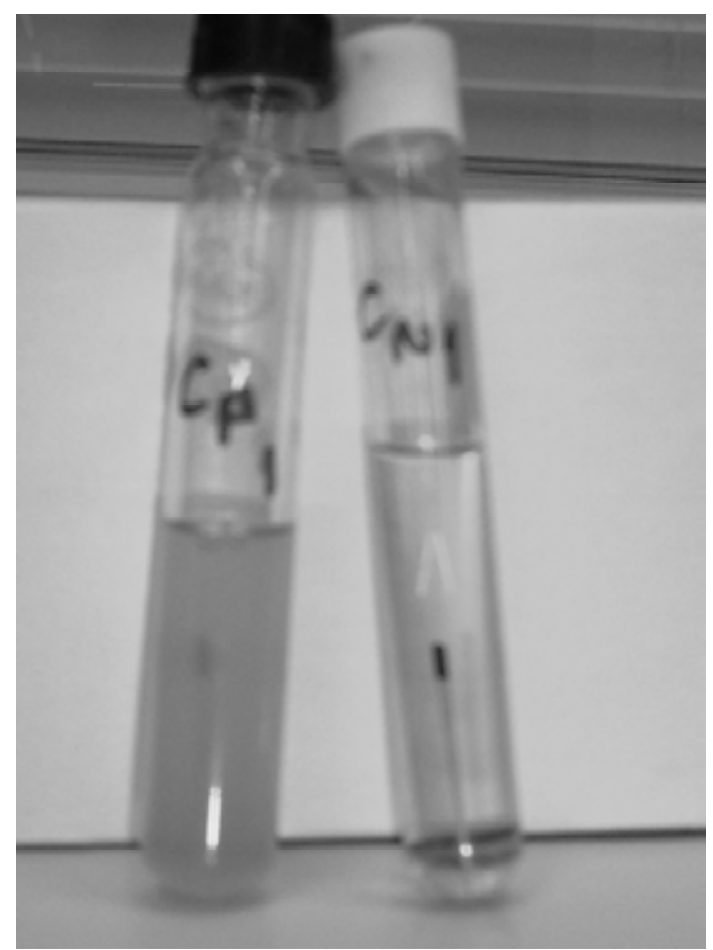

Figura 6 - Tubo 1 com crescimento bacteriano (turvo) e tubo 2 sem crescimento bacteriano (límpido).

evitando-se a contaminação pelo meio externo.

\section{RESULTADOS}

Os resultados avaliados pela observação da existência de bactérias Enterococcus faecalis, através da análise macroscópica (visual) da turvação do meio de cultura, foram considerados negativos, pois houve o aspecto límpido do caldo de BHI nos grupos 1, 2, 3 e 4, demonstrando ausência de crescimento bacteriano em todos os grupos estudados. No controle positivo foram verificados $100 \%$ de contaminação, indicando que as bactérias continuaram viáveis até o final do experimento. Os tubos do controle negativo não apresentaram crescimento dos microrganismos, assegurando a efetividade das soluções empregadas neste experimento. Os dados dos resultados estão apresentados na Tabela 1.

Tanto a solução de hipoclorito de sódio a $5,25 \%$ como a solução de clorexidina a $4 \%$ mostraram-se efetivas sobre o Enterococcus faecalis nos dois períodos experimentais (30 segundos e 1 minuto), eliminando em $100 \%$ o crescimento bacteriano.
GOMES CC,

CAMÕES ICG,

FREITAS LF,

PINTO SS,

SARAIVA SM,

SAMBATI $S$.

AVALIAÇÃO DO

HIPOCLORITO

DE SÓDIO E DA

CLOREXIDINA NA

DESINFECÇÃO DE

CONES DE GUTA-

PERCHA

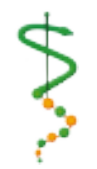

REVISTA DE

ODONTOLOGIA DA

UN I VERS I DADE

CIDADE DE SÃO

PAULO

$2010 ; 22(2): 94-$

103, MAI-AGO 


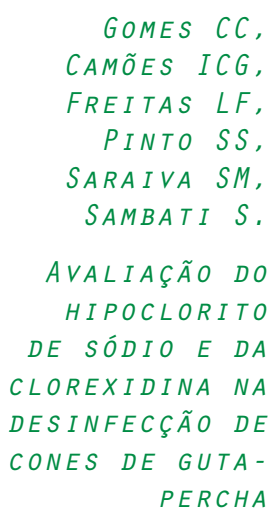

100

TABELA 1 - Resultados obtidos nos grupos analisados, com quantidade de cones de guta-pecha utilizados em cada grupo e percentual de tubos de ensaio com aspecto turvo, indicando o crescimento bacteriano.

\begin{tabular}{ccccccc} 
& Grupo 1 & Grupo 2 & Grupo 3 & Grupo 4 & $\begin{array}{c}\text { Controle- } \\
\text { Positivo }\end{array}$ & $\begin{array}{c}\text { Controle } \\
\text { Negativo }\end{array}$ \\
\hline $\begin{array}{c}\text { Total de cones de guta- } \\
\text { percha }\end{array}$ & 10 & 10 & 10 & 10 & 2 & 8 \\
$\begin{array}{c}\text { Total de tubos de ensaio } \\
\text { com aspecto turvo }\end{array}$ & 0 & $0 \vdots$ & 0 & 0 & 2 & 0 \\
$\begin{array}{c}\text { Porcentagem de tubos } \\
\text { com aspecto turvo }\end{array}$ & $0 \%$ & $0 \%$ & $0 \%$ & $0 \%$ & $100 \%$ & $0 \%$ \\
\hline
\end{tabular}

\section{I S CUSSÃO}

Sabendo-se da necessidade do controle de infecção durante todas as fases do tratamento endodôntico, uma vez que a presença de microrganismos estaria relacionada ao desenvolvimento de doenças pulpares e perirradiculares, faz-se necessário adotar procedimentos técnicos de assepsia, inclusive na obturação dos sistemas de canais radiculares, com a descontaminação dos cones de guta-percha, material mais utilizado nessa etapa, sendo uma condição essencial para o sucesso do tratamento e para a manutenção da saúde do paciente. (Kakehashi et al. ${ }^{3}, 1965$; Morais e Olmedo ${ }^{14}, 1971$; Leonardo et al. ${ }^{5}$, 1997, Lopes e Siqueira Jr ${ }^{10}$, 2004).

Como os cones de guta-percha se mantêm em contato com o periápice após a obturação, devem estar isentos de microrganismos; porém, como não podem ser esterilizados, por serem materiais termolábeis, devem ser descontaminados por agentes químicos, pois podem estar contaminados em suas embalagens lacradas ou serem contaminados durante seu manuseio na prática clínica (Cardoso et al. ${ }^{15}$, 2000).

Várias substâncias químicas antissépticas têm sido descritas na literatura, merecendo destaque as soluções de hipoclorito de sódio e da clorexidina, por serem consideradas potentes agentes antimicrobianos (Estrela et al. ${ }^{7}, 2002$; Redmerski et al. $\left.{ }^{21}, 2007\right)$.

Neste experimento, avaliou-se a eficácia do hipoclorito de sódio a 5,25\% e da clorexidina a $4 \%$ na desinfecção dos cones de guta-percha, por 30 segundos e 1 minuto, previamente contaminados com Enterococcus faecalis, por ser uma bac- téria prevalente na cavidade oral e estar relacionada às infecções endodônticas persistentes.

O presente estudo demonstra que o hipoclorito de sódio a 5,25\% consegue promover a desinfecção dos cones de gutapercha a partir de 30 segundos de contato com a solução, discordando dos achados obtidos por Radcliffe et al. ${ }^{19}$ (2004) que precisaram do tempo de 2 minutos de exposição ao hipoclorito de sódio a 5,25\% para reduzir a zero o número de Enterococcus faecalis, enquanto que, para Gomes et al. ${ }^{7}$ (2001a), o tempo necessário de exposição ao $\mathrm{NaOCl}$ a 5,25\% para inibir a proliferação bacteriana foi a partir de 45 segundos.

Assim como Gomes et al. ${ }^{23}$ (2001b), este trabalho comprova a eficácia do hipoclorito de sódio a 5,25\% na desinfecção de cones de guta-percha previamente contaminados com $E$. faecalis, a partir de 30 segundos de contato dos cones com a solução.

Esta pesquisa comprova a eficácia antimicrobiana contra bactérias Enterococcus faecalis das soluções de $\mathrm{NaOCl}$ a $5,25 \%$ e de clorexidina a $2 \%$, como também foi verificado por Dameto et al. ${ }^{20}$ (2005).

Este experimento encontrou resultados semelhantes ao estudo feito com a clorexidina a $4 \%$ e o hipoclorito de sódio a $5,25 \%$, por um período de tempo de exposição de 1 minuto, para desinfecção de cones de guta-percha previamente contaminados com Enterococcus faecalis (Fagundes et al. $\left.{ }^{18}, 2005\right)$. Nesta pesquisa, ainda ficou comprovado que, nas concentrações citadas, é necessário apenas um período de 30 segundos para a eliminação do E. faecalis da superfície dos cones de 
guta-percha.

Os resultados deste estudo são consistentes com os relatados em outros experimentos como o de Cardoso et al..$^{15}$ (2000) e de Redmerski et al. ${ }^{21}$ (2007), que comprovaram a efetividade da clorexidina a $2 \%$ para a descontaminação dos cones de guta-percha no tempo de 1 minuto.

Recentes estudos de microscopia eletrônica apontam para alterações na superfície dos cones de guta-percha após sua descontaminação com hipoclorito de sódio. Alguns trabalhos observaram que a clorexidina a $2 \%$ não alterou a estrutura do cone e que o hipoclorito de sódio a $5,25 \%$ causou alterações na topografia dos cones de guta-percha após vinte minutos de exposição e na elasticidade após um minuto (Valois et al. ${ }^{24}, 2005 a$; Valois et al. $\left.{ }^{25}, 2005 \mathrm{~b}\right)$. Entretanto, conforme verificado neste trabalho, nas concentrações apresentadas, bastariam apenas 30 segundos de contato com as soluções antimicrobianas para a completa desinfecção dos cones.

Seria interessante que novas pesquisas fossem realizadas com o intuito de se avaliar se as soluções antimicrobianas nessas concentrações trariam alteração à superfície dos cones de guta-percha num período de tempo de 30 segundos, pois poderia tornar-se mais segura sua utilização, garantindo a manutenção da composição e estrutura dos cones de guta-percha.

\section{CONCLUSÃO}

Com base nos métodos experimentais empregados e nos resultados obtidos, pode-se concluir que:

- Ambas as substâncias testadas foram capazes de desinfetar os cones de guta-percha contaminados com cepas de Enterococcus faecalis nos tempos testados.

- O hipoclorito de sódio na concentração de 5,25\% possui ação antimicrobiana efetiva contra o Enterococcus faecalis nos tempos de 30 segundos e 1 minuto.

- A clorexidina a $4 \%$ possui ação antimicrobiana efetiva contra o Enterococcus faecalis nos tempos de 30 segundos e 1 minuto.

A pesquisa foi realizada na Universidade Federal Fluminense.
GOMES CC, CAMÕES ICG, FREITAS LF, PINTO SS, SARAIVA SM, SAMBATI $S$.

AVALIAÇÃO DO HIPOCLORITO DE SÓDIO E DA CLOREXIDINA NA DESINFECÇÃO DE CONES DE GUTAPERCHA

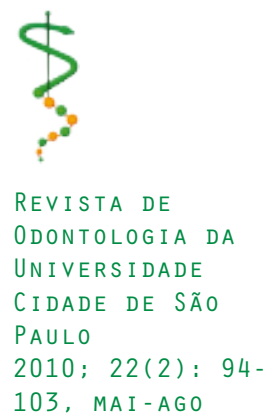


GOMES CC,

CAMÕES ICG,

FREITAS LF,

PINTO SS,

SARAIVA SM,

SAMBATI $S$.

AVALIAÇÃO DO

HIPOCLORITO

DE SÓDIO E DA

CLOREXIDINA NA

DES INFECÇÃO DE

CONES DE GUTA-

PERCHA

102

REVISTA DE: ODONTOLOGIA DA UNIVERSIDADE CIDADE DE SÃO PAULO $2010 ; 22(2): 94-$ 103, MAI-AGO

\section{REFERÊNCIAS}

1 - Gahyva SM, Siqueira Jr JF. Avaliação da contaminação de cones de guta-percha disponíveis comercialmente. J Bras Endo/Perio 2001; 4(6):193-5.

2-Miller W D. An introduction to the study of the bacterio-pathology of the dental pulp. Dental Cosmos 1984; 36(7):505-28.

3-Kakehashi S, Stanley HR, Fitzgerald RJ. The effects of surgical exposures of dental pulps in germ-free and conventional laboratory rats. Oral Surg Oral Med Oral Pathol. 1965; 20(3):340-9.

4 - Machtou PPL. Irrigation en endodontie. Actual Odonto Stomatol 1980; 34(131):38794.

5 - Leonardo MR, Bonifácio KC, André RFG, Silva LAB, Ito IY. Evaluation of the sterility and antimicrobial activity of gutta-percha cones. Bra Endod J 1997; 2(1):51-4.

6 - Siqueira Jr JF, Batista MMD, Fraga RC, Uzeda M. Antibacterial effects of endodontic irrigants on black-pigmented Gram-negative anaerobes and facultative bacteria. J Endod 1998; 24(6):414-6.

7 - Estrela C, Estrela CRA, Barbin EL, Spanó JCE, Marchesan MA, Pécora JD. Mechanism of action of sodium hypochlorite. Braz Dent J 2002; 13(2):113-7.

8- Walker A. A definiter and dependable therapy for pulpless teeth. J Am Dent Ass 1936; 23(2):1418-25.

9- Hauman CHJ, Love RM. Biocompatibility of dental materials used in contemporary endodontic therapy: a review. Part 1. Intracanal drugs and substances. Int Endod J 2003; 36(2):75-85.

10 - Lopes HL, Siqueira Jr JF. Substâncias químicas empregadas no preparo dos canais radiculares. In: Endodontia Biologia e Técnica. $2^{\mathrm{a}}$ ed. Rio de Janeiro: Guanabara Koogan, 2004, cap.18, p.535-579.

11 - Leonardo M, Tanomaru-filho M, Silva L, Filho P, Bonifácio K, Ito I. In vivo antimicrobial activity of $2,0 \%$ chlorexidine used as a root canal irriganting solution. J Endod 1999; 25(3):167-71.

12 - Zamany A, Safavi K, Spangberg LSW. The effect of chlorhexidine as an endodontic disinfectant. Oral Surg Oral Med Oral Pathol 2003; 96(5):578-81.

13 - Basrani B, Santos JM, Tjardehane L, Grad H, Gordusys O, Huang J, et al. Substantive antimicrobial activity in chlorhexidine - treated human root dentin. Oral Surg Oral Med Oral Pathol 2002; 94(2):240-5.

14 - Morais LCT, Olmedo AL. Análise das condições de assepsia dos cones de guta- percha. Rev Gaúcha Odont 1971; 19(2):116-7.

15-Cardoso CL, Redmerski R, Bittencourt NL, Kotaka CR. Effectiveness of different chemical agents in rapid decontamination of gutta-percha cones. Braz J of Microbiol 2000; 31(1): 67-71.

16 - Gomes BPFA, Ferraz CCR, Carvalho K, Texeira FB, Zaia AA, Souza Filho FJ. Descontaminação química de cones de guta-percha por diferentes concentrações de NaOCl. Rev APCD 2001a; 55(1):27-31.

17-Radcliffe CE, Potouridou L, Qureshi R, Habahbeh N, Qualtrough A, Worthington H, Drucker DB. Antimicrobial activity of varying concentrations of sodium hypoclorite on endodontic microorganisms Actinomyces israellis, Actinomyces naeslundii, Candida albicans and Enterococcus faecalis. Int Endod J 2004; 37(27):438-46. 
18 - Fagundes FS, Leonardi DP, Baratto Filho F, Haragushiku GA, Tomazinho LF, Tomazinho PH. Eficiência de diferentes soluções na descontaminação de cones de guta percha exposto ao Enterococus faecalis. Rev Sul-Bras Odontol 2005; 2(2):7-11.

19 - Lima KC, Fava LRG, Siqueira Jr JF. Susceptibilities of Enterococcus faecalis Biofilms to Some Antimicrobial Medications. J Endod 2001; 27(10): 616-9.

20 - Dametto FR, Ferraz CCR, Gomes BPFA, Zaia AA, Texeira FB, Souza Filho FI. In vitro assessment of the immediate and prolonged antimicrobial action of chlorhexidine gel as an endodontic irrigant against Enterococcus faecalis. Oral Surg Oral Med Oral Pathol 2005; 99(6):768-72.

21 -Redmerski R, Bulla JR, Moreno T, Garcia LB, Cardoso CL. Disinfection of guttapercha cones with chlorhexidine. Braz J Microbiol 2007; 38(4):649-55.

22 - Linke HAB, Chohayeb AA. Effective surface sterilization of gutta-percha points. Oral Surg 1983; 55(1):73-7.

23- Gomes BPFA, Ferraz CCR, Vianna ME, Berber VB, Teixeira FB, Souza-filho FJ. In vitro antimicrobial activity of several concentrations of sodium hypoclorite and chlorexidine gluconate in the elimination of Enterococcus faecalis. Int Endod J 2001 b; 34(6):424-8.

24 - Valois CRA, Silva LP, Azevedo RB. Effects of 2\% chlorhexidine and 5,25\% sodium hypochlorite on gutta-percha cones studied by anatomic force microscopy. Int Endod J 2005a; 38(7):425-9.

25 - Valois CRA, Silva LP, Azevedo RB. Structural effects of sodium hypochlorite solutions on gutta-percha cones: atomic force microscopy study. J Endod 2005b; 31(10):74951.

Recebido em: 15/08/2009

Aceito em: 01/10/2009
GOMES CC, CAMÕES ICG, FREITAS LF, PINTO SS,

SARAIVA SM, SAMBATI $S$.

AVALIAÇÃO DO HIPOCLORITO DE SÓDIO E DA CLOREXIDINA NA DESINFECÇÃO DE CONES DE GUTAPERCHA

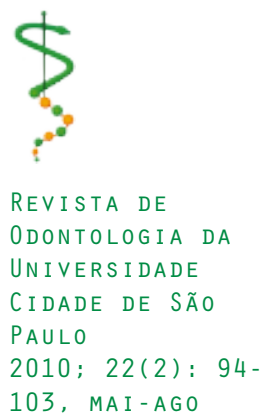

